\title{
The effect of biohumus on the growth of seedlings of Scorzonera tau-saghyz Lipsch. et Bosse in the laboratory
}

Faleyev D.G., Boguspaev K.-K.K.-K., Faleyev E.G., Myrzagaliev J.J.

Scientific-Research Institute of Biology and Biotechnology, Almaty, Kazakhstan, exeko@yandex.ru

Key words: Scorzonera tau-saghyz, Eisenia fetida, biohumus, vermekulturs, rubber doi: 10.36291/HIT.2019.faleyev.060

Scorzonera tau-saghyz is an endemic of Kazakhstan, capable of accumulating up to $40 \%$ of rubber in dry roots in quality not inferior to rubber of hevea. Currently, research is underway to restore the abundance of this species, as well as to develop effective and cost-effective biotechnologies for producing commercial rubber from $S$. tau-saghyz roots $[1,2]$.
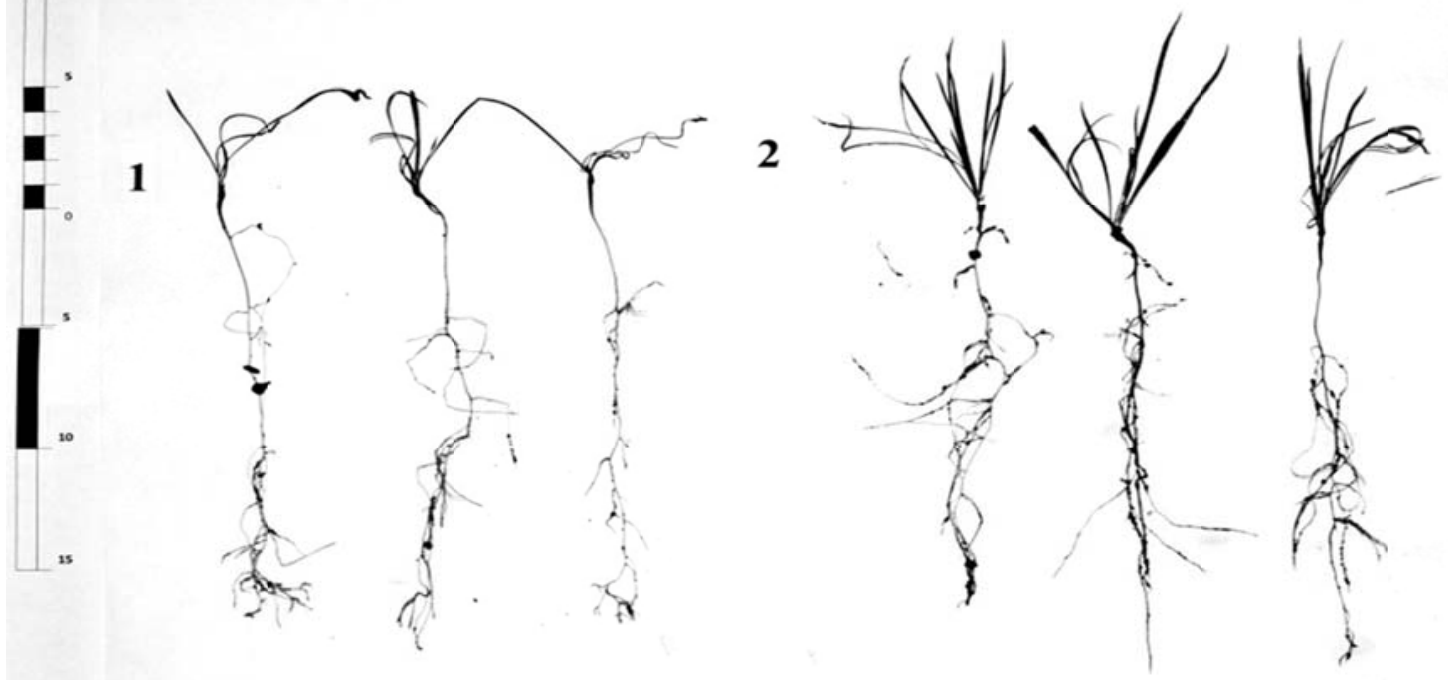

Figure 1. Appearance of the root system of $S$. tau-saghyz seedlings grown without biohumus (1) and with the addition of $20 \%$ biohumus (2) (on day 172 of the experiment).

Laboratory studies have shown that the application of vermicompost in the amount of $20 \%$ contributes to the improvement of growth parameters and survival of seedlings S. tau-saghyz. So, when you make vermicompost average height and number of leaves were almost 1.5 times, the dry weight of the aboveground part of seedlings S. tau-sagyz more than 2 times, the survival rate of seedlings by $7.1 \%$ higher than in the controls. Most of the studied morphological parameters of the root system S. tau-saghyz did not differ significantly, while the number of lateral roots of the main root, and the maximum length of lateral roots adventitious roots 1st order when making vermicompost were, respectively, 2 and 4 times higher than in controls. The use of vermicompost can substantially contribute to the development of cost-effective modern biotechnology aimed at restoring the strength of nature and getting a commercial rubber root $S$. tau-saghyz.

The data obtained can be used in the development of cost-effective modern biotechnology to restore the number of naturally rare and endangered species, rubber tausagyz and a commercial rubber from roots $S$. tau-saghyz.

References

1. Omo-Ikerodah E.E. et al. //African J. Biotechnol. 2009. 8(25):7303-7307.

2. Богуспаев и др. // Вестник КазНУ, серия экологическая. 2013. 2/2(38): 64-70. 